\title{
Identidades musicales híbridas en tres puertos afrocaribeños
}

\author{
Mario Trujillo Bolio
}

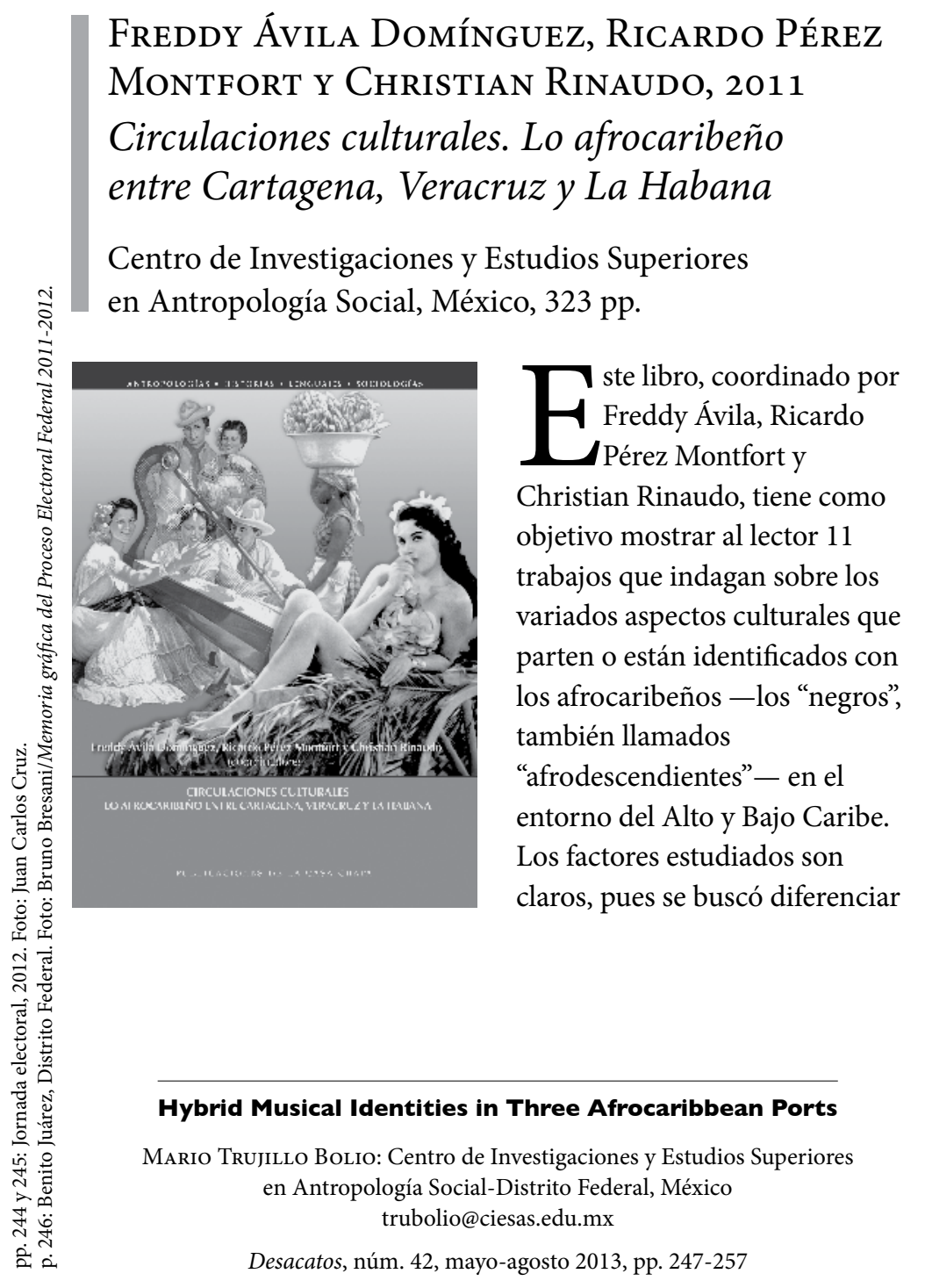

los símbolos y los objetos asociados a la cultura negra en sus dinámicas político-identitarias en las ciudades de Cartagena, Colombia, Veracruz, México, y La Habana, Cuba. Éstos coinciden en tener en su historia la presencia del fuerte colonialismo hispánico, haber sido puerta de entrada para los esclavos africanos y contar con la fortuna de que esté latente desde hace más de cuatro siglos una cultura afrocaribeña determinada en estas urbes portuarias. Las distintas colaboraciones permiten al lector comprender la especificidad cultural de las tres ciudades estudiadas a partir de procesos que pueden estar inmersos en la "globalización", la "transnacionalización" y la “criollización”. Sin embargo, 
también para enriquecer el análisis, es sugerente el párrafo que incorporan los autores de la "Introducción" cuando se remiten a lo escrito por el novelista cubano Antonio Benítez Rojo, en el sentido de que "el Caribe es y será un océano cultural sin fronteras [...] en el cual se mezclan articuladamente lo mágico y lo científico, lo metafísico con lo epistemológico, lo mitológico con lo historiográfico" (p. 13). Los ensayos analizan la noción de "circulaciones culturales" con sus dos posibles significantes: la llamada "circulación desde abajo", que comprende a artistas, intelectuales o militantes, con relaciones translocales familiares,

los que están y viven con la "circulación desde arriba", en la promoción y difusión a gran escala de producciones mercantiles llevadas a cabo por la industria cultural y el turismo.

El apartado I, "La construcción de lo 'afro' en las políticas culturales", inicia con el texto de Christian Rinaudo, titulado 'Lo 'afro', lo popular y lo caribeño en las políticas culturales de Cartagena y Veracruz". Es un análisis del programa del Ministerio de Cultura de Colombia con sus componentes $\mathrm{y}$ acciones como un plan de las políticas culturales contemporáneas en un supuesto rescate de la identidad nacional. No dice que los antecedentes están en la "constricción de la ideología nacionalista del

'blanqueamiento' así como de dar una visión romántica de las poblaciones negras e indígenas" (pp. 41 y 59). El autor hace una advertencia en el sentido de que una de las claves para comprender cómo se plantearon los objetivos de inscripción cultural de la Cartagena costeña en el espacio caribeño durante el siglo $\mathrm{xx}$ reside en la pertinencia y las reformulaciones de movilizaciones colectivas frente a la elite local (p. 40). Señala que este proceso que transcurre entre las décadas de 1940 y 1950, que cataloga como "el renacimiento de una versión cultural vertida hacia el Caribe", estuvo conformado por distintos géneros musicales: el danzón, el son, la guaracha, la rumba, el mambo, el chachachá, y más tarde: el porro, la cumbia, el vallenato y el fandango. Subraya que varios de ellos fueron mediatizados por la industria disquera, el cine y la radio. Empero, distingue que hubo otra ola de movilizaciones antielitistas con actores de la vida literaria y artística local que constituyeron un núcleo renovador de la actividad cultural y literaria con la creación de fundaciones: el Gimaní Cultural, el Cabildo de Negros de Getsemaní y el Instituto de Cultura de Cartagena en 2000 - transformado en el Instituto del Patrimonio y Cultura de Cartagena en 2003-, lo mismo que a través de la revitalización de las Fiestas

de Independencia.

En relación con México, se remite a la creación del Consejo Nacional para la Cultura y las Artes en 1988 y después la del Fondo Nacional para la Cultura y las Artes. Menciona la política de descentralización cultural a nivel federal. Retoma el caso del Instituto Veracruzano de Cultura, que a su parecer desde su creación en 1987 tuvo una verdadera dinámica de reflexión y programas que rompían con la visión centralista de la cultura, como la rutina del son comercial de la radio de los años cuarenta y del cliché "jarocho": vestido de blanco y bailando la bamba para darle presentación al "folclore nacional". A cambio, dice Rinaudo, emergió un grupo que retomó su relación histórica con lo "negro" constituido "por músicos, historiadores y antropólogos, en su mayoría originarios de la región", que buscaron y sacaron del olvido a viejos jornaleros rurales que nunca se profesionalizaron, pero que eran reconocidos en los antiguos fandangos. Este grupo se dio a la tarea de programar encuentros entre jaraneros, talleres y cursos de música y zapateado en Casas de Cultura del Sotavento; después a la de renovar conjuntos jarochos y a difundir un "movimiento jaranero” (pp. 50-51). Para el autor, las consecuencias de lo anterior no son nada promisorias, 
pues no queda de ese movimiento más que la visión inicial de un regreso a la tradición campesina del Caribe afroandaluz que, en efecto, contribuyó a fomentar un nuevo estilo cultural y artístico, pero que ahora es algo distinto a la realidad de antaño.

Lo mismo sucedió con la revalorización del danzón y del son montuno. Algunos promotores culturales buscaron músicos y grupos de la vieja época, como Son del Clave de Oro, Moscovita y sus Guajiros, Quinteto Mocambo y otros, a lo que se agregaría el acervo creado en las décadas de 1980 y 1990 por los festivales Internacional Afrocaribeño en Veracruz, el Internacional Agustín Lara, el del Son Montuno, y la constitución del Centro de Estudios del Caribe. Ubica dos tendencias en este proceso: su surgimiento en el terreno de la investigación académica, dedicada a estudiar la herencia cultural "afro" en el mundo latinoamericano, y la diversidad de las influencias y la creatividad cultural y social de las sociedades regionales que a pesar de que no se identifican como "negras" sí reconocen sus influencias africanas. El balance de esto no es positivo para Rinaudo, pues en la actualidad prevalece la concepción de la cultura "como un instrumento del marketing turístico y más aún en una política cultural dirigida no al pueblo sino al elector que se le da grandes espectáculos de entretenimiento gratuitos y pintados con los colores del hoy partido en el poder" (p. 57).

El segundo ensayo: "Entre el espectáculo y la agencia. Signos afrodescendientes y políticas públicas en Cartagena", de Mauricio Pardo Rojas, es un

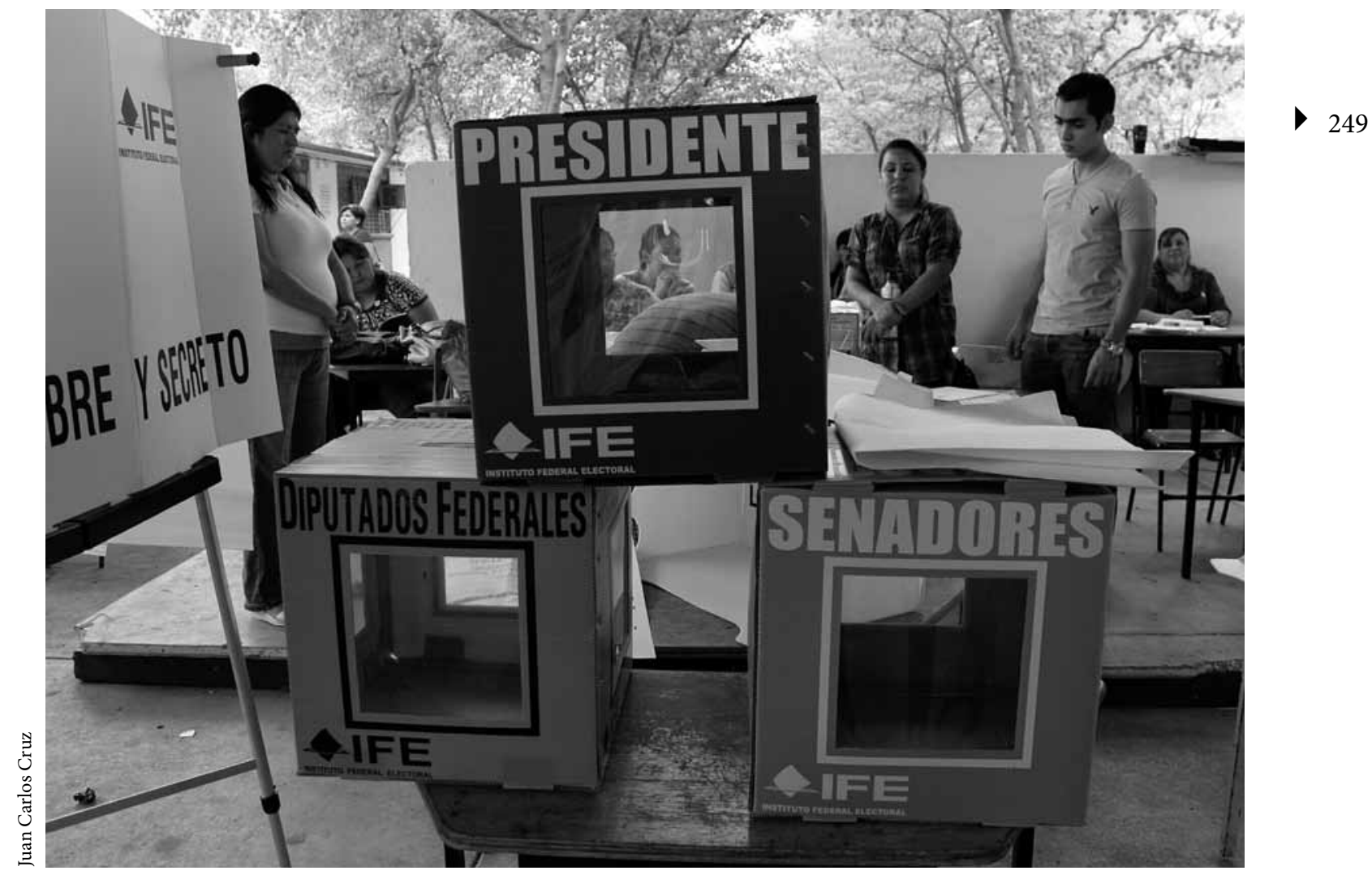

Jornada electoral, 2012. 
lúcido análisis histórico que transita del siglo xvir al xx en la búsqueda en Colombia de la raíz cultural del grupo afrodescendiente y de la circulación de signos afro. Estudia cómo ya desde el siglo XVII los "bundes" bailes y cantos de los esclavizados africanos, en los que participaban indios, mestizos, mulatos y zambos, fueron vedados por las autoridades virreinales de Cartagena sólo porque se dedicaban a tocar, bailar, cantar y beber hasta el amanecer. Nos relata cómo se desarrolló en el siglo XVIII la hibridación cultural de diferentes grupos raciales y en particular en la ritualidad pública festiva - Día de Reyes, de San

\section{Sebastián, de la Virgen de la}

Candelaria, de San Blas, o de los

Esclavos, los días de carnaval a principios de la Cuaresma, Navidad y Fin de Año-, así como "la continuación de las fiestas por los cabildos de las naciones africanas después de desfilar en comparsas en las calles de Cartagena y escuchar misa en el cerro de la Popa" (pp. 71-72). Finalmente la población negra terminaba en espacios públicos compartidos y celebraba al aire libre y al son de los tambores. Pardo Rojas refiere que a principios del siglo XIX la población negra ocupó las posiciones económicas y sociales más bajas y que estaba confinada a las peores situaciones de pobreza y marginalidad en los arrabales del oriente de Cartagena. En tiempos de las alianzas de liberales y conservadores las prácticas festivas de los afrodescendientes fueron reprimidas, ya que "dejaron de ser vistas por la clase dominante con cierta condescendencia y pasaron a ser consideradas signos de barbarie y atraso". Los desfiles de comparsas con música de tambores de los barrios sólo aparecieron en las festividades públicas de manera marginal en los desfiles patrioteros oficiales. No obstante, en los desfiles de la población afrodescendiente y en las fiestas de diciembre estuvieron presentes los "fandangos con cantadoras que improvisaban coplas al ritmo de tambores" (p. 74).

$\mathrm{El}$ autor indica que a principios del siglo xx la música cubana ingresó a Cartagena en las clases medias y altas "vestida de orquesta y de baile de salón" y en la década de 1920 se hizo sentir a través de partituras, cilindros y fonógrafos con una diversidad de ritmos, como el danzón, el porro, el son, el changüí y los picos. Los negros colombianos aprendieron de los obreros cubanos y formaron sextetos para tocar sones $y$ changüíes que no tardaron en extenderse a los barrios citadinos de negros. Pero los formatos orquestales internacionales condujeron a que las músicas afrodescendientes cartageneras y costeñas de tambores vernáculos originales fuesen reemplazadas por la batería y la percusión cubana de bongós, tumbadoras y timbales. La conclusión de Pardo Rojas es que en la década de 1930 "las músicas afrodescendientes cartaginesas y costeñas fueron vertidas a formatos cosmopolitas, en los que 'lo negro' quedaba como una referencia anecdótica exótica" (p. 77). Lo interesante de este estudio histórico de larga duración es que desentraña el radicalismo folclórico y el realismo social mulato en la segunda década del siglo xx, así como la banalidad mediática y el mercantilismo que sofocan las fiestas populares que aún tienen contenidos musicales afrodescendientes. Una muestra de ello fue el movimiento cultural de la década de 1980 en Getsemaní, barrio legendario de Cartagena y de movimientos sociales que han concentrado su trabajo en el fortalecimiento cultural y lo lingüístico del palenque. Pardo Rojas afirma que en pleno siglo Xxi la presencia de los afrodescendientes en las ciudades, en el litoral, en las islas y en los barrios no deja de recrear las prácticas culturales en su lenguaje, en sus formas sociales, en sus fandangos o cumbias, en sus porros, en su salsa, en su champeta.

Lorraine Karnoouh colaboró con el artículo "Lo 'afro' en el imaginario nacional cubano 
y el contrapunteo caribeño entre La Habana y Santiago de Cuba”. Menciona que en Cuba la noción de lo "afro" y su uso como categoría de identidad social pueden entenderse dentro de la propia formación sociohistórica de la comunidad social cubana protagonizada por los esclavos, los obreros negros y los mulatos. En este contexto, el ideal del mestizaje positivo y el cuestionamiento a la legalidad segregacionista tienen que ver con el discurso de la elite criolla habanera en términos de "patria", más adelante con su reclamo final de la "independencia" y después con una ficticia unidad nacional en la que se imbrican blancos, negros, mulatos, esclavos liberados y terratenientes. Empero, la autora asegura que en la construcción del Estado-nación cubano estuvo presente la exclusión del "negro" y que sólo la alteridad negra se incorpora a la identidad cubana siempre y cuando se mantenga el sentido paternalista, en el que no deja de predominar una jerarquización entre la alta cultura y el folclore. En la década de 1930 prevalece en la isla el auge del afrocubanismo con la figura de Nicolás Guillén y la revalorización del carácter mulato de la identidad cubana. Una empresa pionera en el tema es la Sociedad de Estudios Afrocubanos. Con la Revolución de 1959 se intentó "poner fin a todo vestigio de discriminación racial" y dar "solución definitiva del problema negro". Sin embargo, en pleno proceso revolucionario "se siguió llevando a la política cultural una propuesta unificadora con enfoque folclorista, heredada de la República y su legados", léase Conjunto Folclórico Nacional y Museo de Guanabacoa, y la música y las danzas religiosas se rescataron en sus dimensiones estética y artística. Karnoouh señala que se movilizó lo "afro" como argumento político en el ámbito del internacionalismo. Por otro lado, la autora ve el simbólico caribeño desde la metáfora del contrapunto, sobre todo en dos ciudades cubanas: La Habana - centro políticoadministrativo y sus instituciones: Conjunto Folclórico Nacional, la Casa de África, el Centro Cultural Africano Fernando Ortiz-y Santiago de Cuba, donde surgió el imaginario cubano, es decir, "lo cubano", así como los intercambios de los santiagueros con los franceses e ingleses - con migraciones de haitianos y jamaiquinos- en el Caribe y la ciudad "afro", al igual que con los mitos fundacionales de la nación cubana mestiza. De ahí que esta ciudad haya sido la sede del Festival de las Artes Escénicas de Origen Caribeño en 1981, conocido como Festival Caribe en 1983. No hay que hacer a un lado el significado del Carnaval de Santiago, con sus desfiles, su conga y comparsas. Hay un aspecto que vale la pena retomar: en el contrapunto se juega la contradicción fundamental de la relación con lo "afro" de Cuba, considerado todavía, a pesar de todo, como un elemento de alteridad, pero también como símbolo de la autenticidad, de lo propio, de lo cubano (p. 108).

El apartado II,

"Mercantilización y puesta en escena", inicia con el texto de Ricardo Pérez Montfort: "Postales de las Antillas. Estereotipos y negros en la imagen comercial del Caribe, 1900-1950". De entrada, el historiador de la cultura hace notar que en muchas postales "las referencias visuales e imaginarias de quienes la promovieron y comercializaron se limitaron a sólo cinco aspectos: el paisaje, la sensualidad de las mujeres mulatas y negras, la infraestructura portuaria y hotelera y sus ritmos musicales de clara influencia africana" (p. 115). El autor se ubica entre el fin del siglo xIx y todo el xx para estudiar "algunas vertientes y perspectivas extranjeras que contribuyeron a armar y difundir una idea estereotipada del Caribe, algunas veces infestada de racismo y otras de simple ignorancia pero todo para utilizar a las postales como un vínculo del simple comercio y la transacción” (p. 118). Al venir los tormentosos aires nacionalistas $y$ a fin de diferenciar las especificidades locales para que los discursos exaltaran el orgullo 


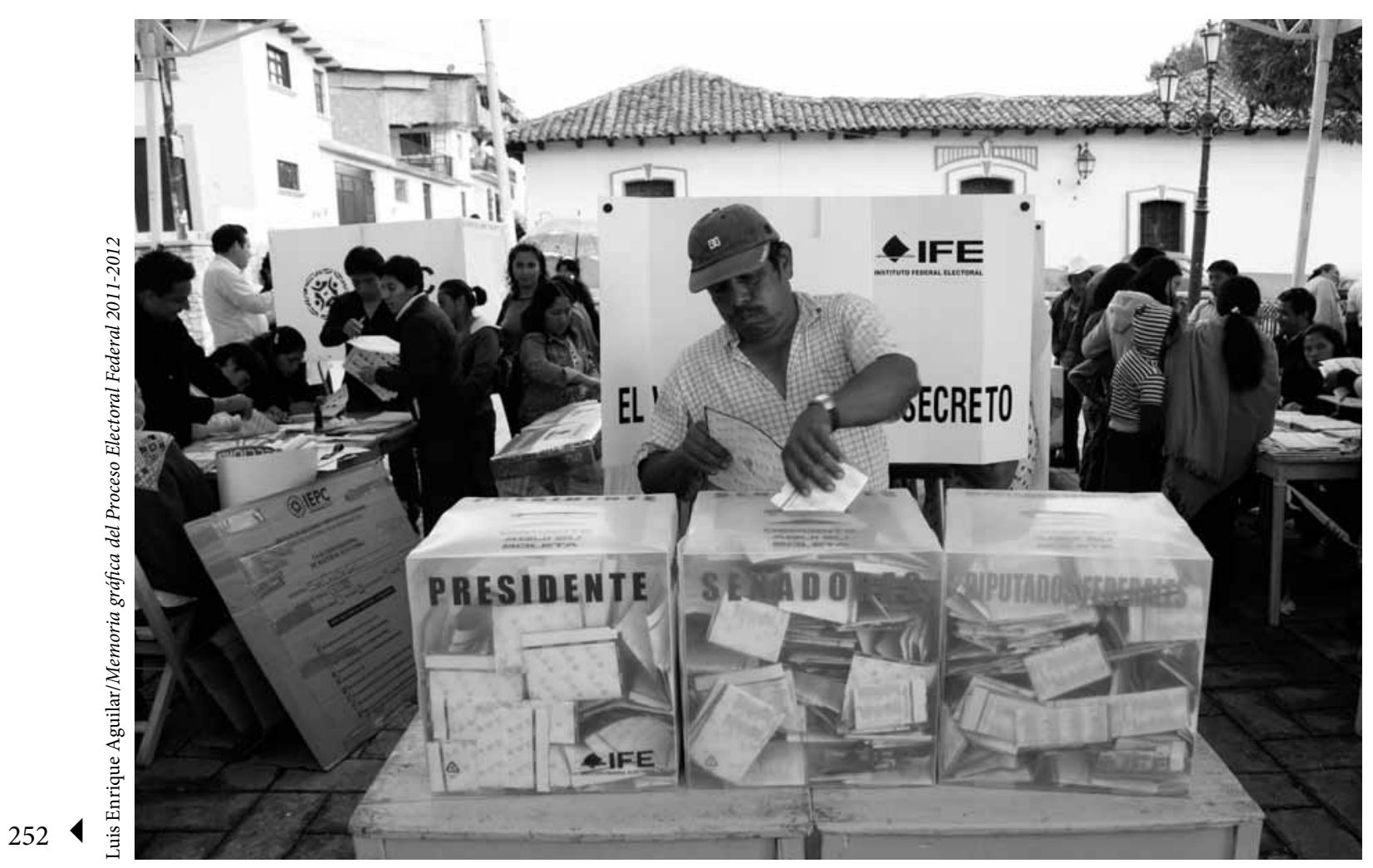

San Cristóbal de Las Casas, Chiapas, 2012.

regionalista, Pérez Montfort destaca que inclusive comenzaron a emerger los términos

subregionales, como "lo cubano", "lo santiagueño", "lo jarocho", "lo barranquillero" o "lo cartaginero". No obstante, cuestiona que en los discursos estatales de corte popular-oficial de los años cuarenta y cincuenta se advierta un desconocimiento de la historia compartida, precisamente, en tres vertientes de sus raíces civilizatorias: la indígena, la hispana y la africana. Pese a lo anterior, encuentra las claras semejanzas "que podían evidenciar los orígenes culturales comunes en el área caribeña y los ricos ejemplos pueden ser en el fandango y sus manifestaciones festiva y popular con música, danza y lírica" (p. 126).

El trabajo presenta otra tesis de la que se dice que "muchos creadores de los estereotipos caribeños tendieron a unificar $y$, a la vez, a diferenciar, gran cantidad de variantes en materia de expresión cultural popular que por demás recurren a su simplificación precisamente por vender un concepto, una trayectoria, una imagen" (p. 127). Esto ha resultado así en gran medida por el auge que ha tenido el Caribe como destino turístico, con sus estereotipos banales de expresión cultural popular y en donde se reúnen la experiencia vacacional, los intereses de comerciantes y los empresarios locales y extranjeros. La postal por sí misma y en "su mensaje breve y su imagen de impacto permitió comunicar una visión compactada del mundo caribeño", que además "ayudó a reducirlo y a construir su dimensión esterotípica en pinturas, fotografías y grabados de un mundo caribeño idealizado", y lo mismo ocurrió en el caso de la litografía y el grabado, como 
lo mostraron los cubanos Víctor

Patricio de Landaluze y Miguel de Villa en el libro Tipos $y$ costumbres de la Isla de Cuba, aparecido en 1881. A decir de Pérez Montfort, la fotografía que ya aparece en 1840 en Cuba, México y Colombia captó las geografías exóticas y tropicales, pero su acción misma no dejó de tener una versión parcial de la realidad y una función comercial. Resalta en este sentido lo realizado por artistas y fotógrafos extranjeros y locales que ofrecían materiales visuales dirigidos a una estimulación de imaginarios. Son varios los ejemplos: en Cartagena de Indias las llamadas "palenqueras" exaltando su vestimenta florida, en Veracruz los "jarochos" que cantan y bailan sus sones con sus guayaberas blancas y las mujeres con sus trajes de fiesta pretendiendo mostrar un cuadro típico del folclore local.

El artículo de Peter Wade, intitulado "La mercantilización de la música 'negra' en Colombia en el siglo xx", es un balance sobre lo que ha sido la mercantilización y el consumo de la música y artistas negros. Se refiere a la trascendencia que tuvieron en el siglo pasado los productos culturales de corte popular vendidos en infinidad de ciudades, como las de América Latina, así como la difusión masiva de supuestas "rumbas" en cintas cinematográficas producidas en los estudios de
Hollywood. Aunado a lo anterior, el estudio profundiza en el impacto que tuvo en la cultura la industria disquera y la comercialización temprana de la música en Colombia. Detalla lo que fue el fenómeno llamado "afro", que se convirtió en una empresa impulsada por el mercado transnacional o globalizante a través de la febril actividad de la disquera RCA Victor y Brunswick de buscar talentos. Respecto de Colombia se remite al caso de Jorge Añez, que grabó bambucos en Nueva York, pero también boleros y rancheras. Este proceso es catalogado por el autor como un eclecticismo musical y un oportunismo comercial por parte de los arreglistas que representaban los intereses de las disqueras. Advierte lo que fue la emergencia de la cumbia, el porro y otros estilos costeños - de evocaciones negras-que tuvieron auge en las décadas de 1940 y 1950, y que Cartagena y Barranquilla fueron los centros de mayor esplendor de la música costeña. También se retoma el papel jugado por disqueras nacionales como Fuentes, Tropical y Atlantic. Wade nos ofrece una visión sobre la importancia de las radiodifusoras colombianas en la difusión de la música costeña. Me parece que debería profundizar más sobre este aspecto en investigaciones posteriores, pues para esos años la radio fue, más que el cine, el medio principal, no sólo para promover y vender las producciones discográficas, sino para fomentar un producto cultural para las mismas clases subalternas. A la pregunta de ¿qué tan negra era la música costeña colombiana comercial?, Wade trata de responder que esa música negra se convirtió en vanguardista al simbolizar la tradición y autenticidad de la cultura colombiana, y porque a su vez "simbolizaba la excitación y las libertades sexuales".

El sexto artículo del libro corresponde a Nahayeilli Juárez, que estudia "Lo 'afro' en las industrias de la música y el cine: el caso afrocubano en México".

Bien dice la autora que la circularidad de lo "afro" y lo afrocubano en las ciudades de México y Veracruz no es comprensible en el siglo $\mathrm{xx}$ si no se toman en cuenta los medios de comunicación y las empresas musicales transnacionales. Juárez afirma que se grabaron 319 danzones en acetatos de las disqueras Columbia y RCA Victor, y que el son cubano, la guaracha y la conga fueron introducidos por la producción de discos de la industria de la música - que obtuvo ganancias millonarias-, bien aceptados en la capital mexicana y, desde luego, como música de fondo de las comparsas de carnavales de Veracruz. Es cierto, todo esto ya se ubica en una época caracterizada por una fuerte interinfluencia musical y 
de la industria del espectáculo presente en la radio del hogar, en el cabaret con orquestas, en los teatros con presentaciones de rumberas y en los salones de baile con músicos que amenizaban en vivo a los que acudían distintos sectores de la sociedades capitalina y porteña. Habría que añadir el gran influjo posterior de las primeras radiodifusoras como la XEw, que promovía a músicos y cantantes afrocubanos con el bolero, el son y el mambo. La lista no deja de ser larga: Dámaso Pérez Prado, Miguelito Valdés, Ignacio Villa "Bola de Nieve" y Rita Montaner. Lo que asevera la autora resulta sugerente en el sentido de que la rumba se incorporó a los repertorios

musicales de las obras de teatro y en el marco escenográfico fueron representados personajes como el negro y la mulata. Es importante advertirlo, pues estos estereotipos fueron adaptados de manera más sofisticada a la gran industria cinematográfica mexicana de la década de 1940. Juárez retoma en el melodrama promovido por la industria cinematográfica mexicana las tres vertientes de origen cubano con sus distintos ritmos, que Carlos Monsiváis definió de manera magistral: el populismo de barriada, el género de las cabareteras y el género del amor familiar. Después de hacer un notable repaso de los melodramas de cabareteras protagonizados por las rumberas cubanas en cintas como Venus de fuego, Mulata, Pervertida, Delirio tropical, Víctimas del pecado o Qué bravas son las costeñas, la autora logra diferenciar los estereotipos más representativos de las mulatas y negras en la "época de oro" del cine mexicano (pp. 171-173).

Freddy Ávila desarrolla el artículo "Lo 'afro' en el discurso turístico de Cartagena: subexposición y sobreexposición". Al observar a Cartagena de Indias a través de guías turísticas, folletos, catálogos, libros ilustrados y páginas web, con antecedentes y fuentes teóricas para respaldar su investigación, Ávila nos ofrece algunas conclusiones de sus pesquisas. A partir de la utilización de la metáfora "subexposición y sobreexposición" nos dice que lo "afro" para el discurso y práctica turísticos es sólo algo que vende, una mercancía, que también se comercializa la ciudad de mar como Primer Centro Turístico de la República, como un Patrimonio Histórico y Cultural de la Humanidad, un Distrito Cultural, sede del IV Congreso Internacional de la Lengua Española, del Festival Internacional del Cine de Cartagena de Indias, el Hay Festival de Cartagena y otras lindezas, como el Concurso Nacional de Belleza. Ávila plantea que en la definición de "turismo cultural" no encuentra necesariamente respaldo en que Cartagena haya sido declarada
Patrimonio Histórico, sino porque no está representado el bagaje cultural de la población negra que aparece en el discurso turístico local, en cuanto a ofertar turísticamente barrios como San Diego y Getsemaní, "este último de interés histórico, pues ahí fue donde se gestó la Independencia de Cartagena, lidereada por muchos negros y mulatos que vivían en el lugar" (p. 203). El discurso turístico no incluye la condición de los negros segregados por habitar extramuros de la muralla. Asimismo, destaca que las llamadas "palenqueras" con el oficio de comerciantes - mujeres que llevan una palangana con frutas en el recorrido de calleses un símbolo sobreexpuesto en el discurso turístico, pues pierde contenido como resultado de la fijación proyectada sobre su cuerpo negro. En sus conclusiones, el autor advierte que los elementos culturales "afro" en su nueva condición sobreexpuesta no hacen sino confirmar su instrumentalización y la lógica mercantilista que anima a los diferentes agentes que operan el sector turístico. La reflexión sobre el lugar de lo "afro" debe hacerse sobre principios de participación democrática y de responsabilidad social en el terreno mismo de la planificación de las políticas públicas.

En cuanto al apartado III, "Los actores de la circulación cultural”, 
Stefania Capone presenta su trabajo "Conexiones 'diaspóricas': redes artísticas y construcción de un patrimonio cultural 'afro"'. De entrada, anota que el debate acerca de los procesos de institucionalización y patrimonialización de elementos culturales tiene que prescindir de un análisis de la circulación de ideas en las que estén implícitos los intercambios y las influencias mutuas entre África y la llamada “diáspora negra”. Así, ubica su objeto de estudio en la circulación de intelectuales $\mathrm{y}$ artistas negros entre Estados Unidos, el Caribe, Brasil y África.
Realiza un recuento de

movimientos artísticos a partir

del Harlem Renaissance con sus

presentaciones en el Apollo

Theatre y el Cotton Club, así como de la significativa influencia alcanzada en la renovación de las artes negras con base en la herencia afroestadounidense sobre los militantes del nacionalismo cultural de las décadas de 1960 y 1970

(pp. 218-219). Respecto de la actividad dancística, Capone se centra en lo que ella denomina "patriarcas de la danza artística negra": Katherine Dunham y Pearl Primus. Si bien, la actividad de Dunham para la autora "ejerció la influencia más profunda sobre la historia de la danza negra" e inauguró la metamorfosis que ésta ha sufrido al entrar en contacto con las culturas que los africanos habían encontrado en Estados Unidos. En tanto, de Primus resalta su contribución al establecer los parámetros para la realización de las danzas nacionales africanas al estandarizarlas desde sus propias investigaciones dentro de la "diáspora negra". Otro aporte de este trabajo es el recuento de la trayectoria de Abdias do Nascimiento - actor y

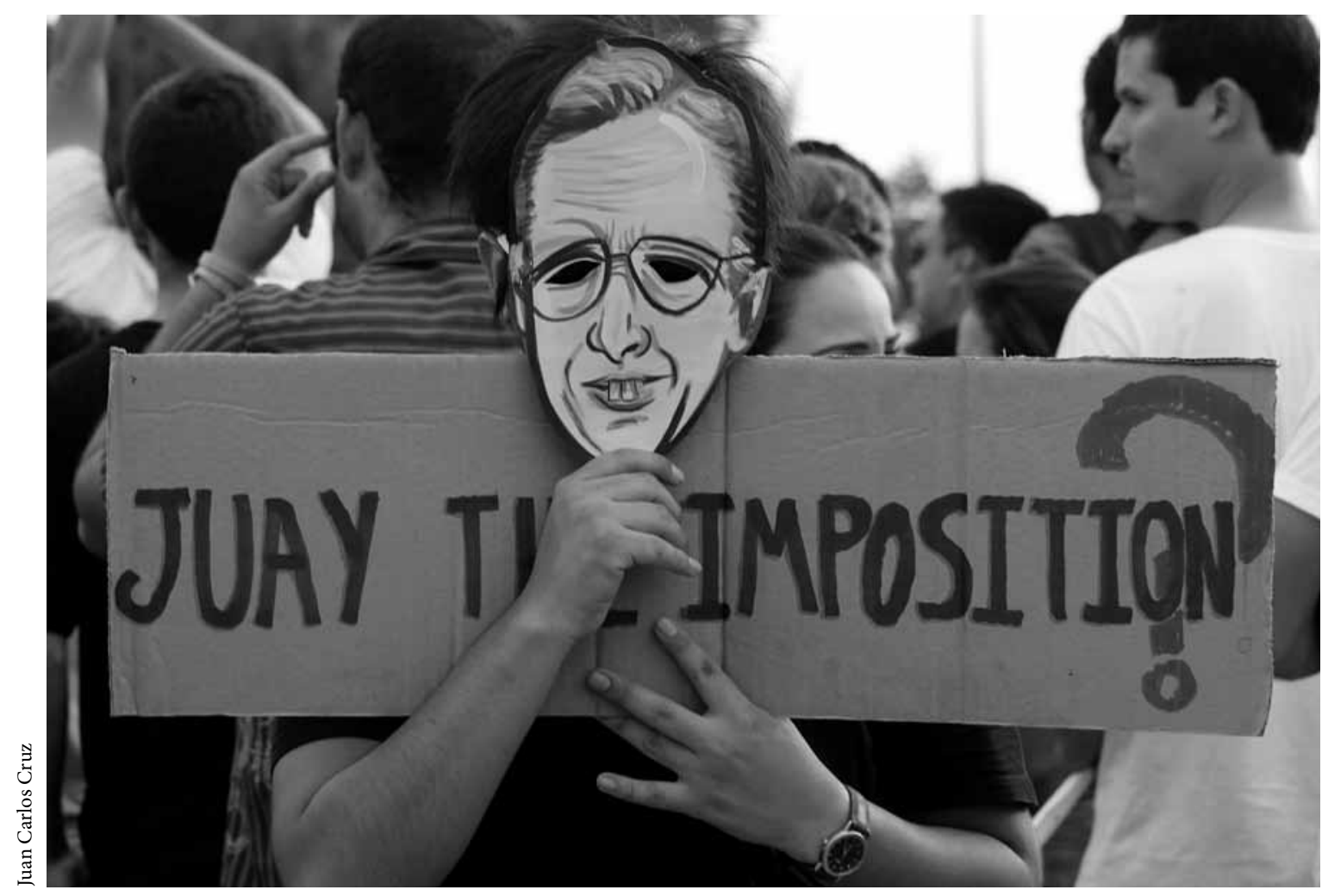

Protestas antipeña, 2012. 
dramaturgo brasileño, militante político de la causa afrobrasileña desde el Frente Negro Brasileño $y$ a partir de su labor en el Congreso Afrocampineiro, fundador del Teatro Negro y el Teatro Experimental do Negro en São Paulo- como uno de los constructores de un patrimonio cultural “afro". Montó y actuó en obras con base en una dramaturgia negra, con personajes negros centrales, no como actores relegados a papeles cómicos subalternos. Una contribución especialmente interesante de Stefania Capone es aquella que enfoca el sentido de que la construcción de la tradición de la coreografía negra resulta de las intensas tes, intelectuales y artistas, quienes circulan e intercambian sus teorías de un continente a otro. Su planteamiento final es muy sugerente: la danza, como expresión del ritmo orgánico ancestral, llega, entonces, a ser el locus principal de la memoria y de la cultura africanas.

Bernardo García Díaz tituló su ensayo: "El puerto de Veracruz, cabeza de playa de la música cubana”. En él hace un raudo recuento histórico de las raíces del cubanismo en el principal puerto novohispano:

el chuchumbé se extiende por las calles de Veracruz en 1776 como un baile que haría furor entre negros, mulatos, soldados,

marinos y, en definitiva, el pueblo llano. Se dice que se bailaba con meneos, zarandeos, manoseos y abrazos hasta dar vientre con vientre $[\ldots]$ sus versos, que se burlan de los religiosos y de la muerte y se regocijan en ligar la sexualidad con cosas santas (p. 247).

Perfila lo que para él es una singular impronta afrocubana, que ningún otro puerto de México tendría. Sus tesis son: 1) Veracruz admitió a los "secuestrados" de África y muchos de ellos llegaron para quedarse en este puerto; 2 ) la presencia de la población afrodescendiente persistirá después del final de tiempos coloniales y la marca mulata se prolongará claramente al menos hasta la primera mitad del siglo $\mathrm{xx}$. Un tema interesante en el trabajo de García Díaz es ubicar el flujo migratorio entre Cuba y Veracruz para conocer la rica vida cultural asociativa. Señala que ha tenido un lugar especial el danzón y que en 1881, un año después de la fecha de su aparición, "ya sonaba en la Plaza de Armas de Veracruz, tocado por la banda municipal, el danzón denominado Malaca" (p. 250). Hay que encontrar la transculturación a través del mar en los artesanos emigrados, fabricantes de puros, apasionados en tocar instrumentos musicales, como el contrabajo, los timbales, el violín y el clarinete, e incluso conformar grupos orquestales.
A inicios del siglo $\mathrm{xx}$ en los bailes que se hicieran en el Centro Recreativo de Obreros, las orquestas de Severiano Pacheco y "Albertico" Gómez estuvieron constituidas por 12 maestros artesanos que no sólo tocaban danzones cubanos, sino también de factura jarocha.

Al leer a Bernardo García Díaz se comprende mejor el significado del cubanismo en la cultura mexicana actual. Indica que proviene de mediados de la segunda mitad del siglo xx con el legendario grupo Acerina y su Danzonera y sus presentaciones en el Salón México. Lo mismo puede decirse en relación con el son y sus representaciones en cuartetos, sextetos y septetos, como el Trío Matamoros, la Estudiantina Sonora Matancera y el Sexteto Boloña, que en México fueron escuchados en discos de la RCA Victor y en las radiodifusoras del puerto de Veracruz: la XEV, "Eco de Sotavento", y la XETF, "La Voz de Veracruz". Sin tapujos, el autor asevera que Veracruz se convirtió en la patria de la música cubana por excelencia y en la cabeza de playa para proyectarla al resto del país. Sus ejemplos son completamente verídicos en la trascendencia que tuvieron grupos y artistas, como Son Clave de Oro, Manuel Peregino con su Trío Caribe, después el Trío Peregrino, Toña "la Negra”, Mario Ruiz Armengol, Pedro Domínguez Moscovita y "Güicho" Iturriaga. Bernardo García Díaz dedica un 
último apartado a la "época de oro" de la música cubana en Veracruz. En la década de 1950 se vive en el puerto lo que define como "verdadera fiebre de música afrocubana". Son los tiempos de los conjuntos que tuvieron trompetas, cantantes, congas y bongós, un tres y un bajo, como fueron Tropical de Veracruz, Tropical Copacabana, Anacaona, Cienfuegos Caribe y Siboney. Además, hubo espacio para danzoneras como la de Los Chinos Ramírez, Alma de Sotavento y la Villaverde, entre otras; para el bolero cubano con distintos tríos veracruzanos y de corte antillano, "el Negro" Peregrino, hermanos Cantarell; también para las sonoras, como la Veracruz, Sotarrivas; para el mambo, con la presencia de Dámaso Pérez Prado y Memo Salamanca; para las grandes orquestas cubanas en el puerto, como la de Benny Moré. García Díaz concluye con lo realizado en los últimos 20 años. Le entusiasma el relevo generacional con grupos de soneros nativos y de son montuno, y advierte que están presentes y son almas mexicano-caribeñas que deambulan todavía por la costa veracruzana exclamando en sus interpretaciones musicales que "no muera el son".

El penúltimo artículo del libro es de Kali Argyriadis y lleva por título "De instructores, asesores y promotores: redes de artistas cubano-veracruzanos y relocalización de repertorio afrocubano". La autora logra diferenciar lo que actualmente es la circulación de artistas veracruzanos con una tradición cultural afromestiza, cuyo repertorio musical y coreográfico es testimonio de las distintas etapas de transnacionalización de la música cubana que se forjó en la isla, en Nueva York, el puerto jaracho y la ciudad de México. Nos advierte de esa nueva generación de músicos de Veracruz y de Xalapa y de los promotores culturales cubanos que se imbrican en las interesantes redes rituales - con la santería como práctica religiosa presente el Día de Brujos en Catemaco en la región de los Tuxtlas- y las prácticas artísticas de profesores cubanos en la Escuela de Arte de La Habana y su interacción cultural con nuevos significados locales, como el ejemplo con análisis etnográficos y culturales. El último artículo del libro es de Édgar J. Gutiérrez Sierra: "Los cabildos de negros en Cartagena de Indias". Es un aporte enriquecedor, pues encuentra las raíces de la cultura afrodescendiente precisamente en la detenida indagación histórica en el entorno de lo que fueron los cabildos negros en Cartagena de Indias y sus prácticas de resistencia con su mundo religioso, sus tradiciones dancísticas y ceremonias. Asimismo, incluye la reconstrucción histórica, la presencia social, política y sobre todo cultural del cabildo de negros como imaginario social en las fiestas de la Virgen de la Candelaria y en los carnavales de Semana Santa. No por nada su enfoque se centra en el barrio popular de Getsemaní, cuna de intelectuales, folcloristas, poetas y coreógrafos con ascendencia africana que hoy en día tiene el poder de convocar a varios grupos afrocaribeños de Cartagena y de otras regiones costeñas de Colombia. 